\title{
Development of experimental and modelling tools for the characterisation of the thermo-electro-mechanical behaviour of composite materials for aircraft applications
}

\author{
Marco Gigliottia $^{\mathrm{a}}$, Marie-Christine Lafarie-Frenot and Jean-Claude Grandidier \\ Institut Pprime, CNRS - ENSMA - Université de Poitiers, Département Physique et Mécanique des Matériaux, \\ ENSMA - Téléport 2 - 1 avenue Clément Ader, BP 40109, 86961 Futuroscope Chasseneuil Cedex, France
}

Received 10 September 2010, Accepted 24 January 2011

\begin{abstract}
The present paper is concerned with the thermoelectric behaviour of CFRP composite samples subjected to DC currents in view of developing experimental and modelling tools for the characterisation of the thermo-electro-mechanical behaviour of composite materials for aircraft applications. DC currents up to $8 \mathrm{~A}$ are injected through the specimens end sides by employing several different electrode techniques whose performances are assessed and compared. Sample and electrode contact resistances are measured for different values of the injected current. The transient and permanent temperatures fields promoted by the injected currents are experimentally measured by infrared thermography. The temperature fields are simulated numerically by a thermoelectric coupled model employing the ABAQUS ${ }^{\circledR}$ FE commercial code; temperatures can be also approximately calculated by a simple lumped parameter model discarding thermal conduction. The comparison between simulations by the models and measurements allows employing the simplified model as a tool to design thermo-electro-mechanical tests.
\end{abstract}

Key words: Polymer-matrix composites (PMC) / thermoelectric coupling / electrical resistance / contact resistance / infrared thermography / thermoelectric numerical coupled model

Résumé - Développement de moyens expérimentaux et de modélisation pour la caractérisation du comportement thermo-électro-mécanique de matériaux composites pour applications aéronautiques. Ce travail concerne le comportement thermoélectrique d'échantillons composites à fibres continues de carbone et à matrice époxyde traversés par des courants électriques continus. L'objectif est de développer des outils expérimentaux et de modélisation nécessaires à la caractérisation du comportement thermo-électro-mécanique de matériaux composites à applications aéronautiques. Des courants continus d'intensité inférieure ou égale à 8 A sont injectés aux extrémités d'échantillons en employant plusieurs techniques et différentes électrodes dont les performances sont évaluées et comparées. Les résistances de contact sont mesurées pour différentes valeurs du courant injecté. Les champs de température transitoires et stationnaires engendrés par les courants injectés sont mesurés expérimentalement par thermographie infrarouge. Les champs de température sont simulés numériquement à l'aide d'un modèle couplé thermo-électrique utilisant le code éléments-finis commercial ABAQUS ${ }^{\circledR}$; les températures stationnaires sont également calculées à l'aide d'un modèle analytique simplifié établi sur la base des observations expérimentales. La comparaison des résultats obtenus par ces deux modèles aux valeurs expérimentales autorise l'utilisation du modèle simplifié pour la conception d'essais thermo-électro-mécaniques.

Mots clés : Matériaux composites à matrice polymère / couplage thermoélectrique / résistance électrique / résistance de contact / thermographie infrarouge / modèle numérique thermoélectrique couplé

\footnotetext{
${ }^{a}$ Corresponding author: marco.gigliotti@lmpm.ensma.fr
} 


\section{Nomenclature}

\begin{tabular}{|ll|}
\hline$R_{\mathrm{m}}$ & Measured resistance \\
$R_{\mathrm{s}}$ & Sample resistance \\
$R_{\mathrm{e}}$ & Electrode resistance \\
$R_{\mathrm{c}}$ & Contact resistance \\
$L_{x}$ & Sample length \\
$L_{y}$ & Sample width \\
$e$ & Sample thickness \\
$e_{0}$ & Total thickness of the $0^{\circ}$ plies \\
$\rho_{\mathrm{f}}$ & Fibre resistivity \\
$V_{\mathrm{f}}$ & Fibre volume fraction \\
$\rho$ & Local material density \\
$T$ & Temperature \\
$t$ & Time \\
$c_{v}$ & Specific heat \\
$r$ & Coefficient of electrical resistivity \\
$\boldsymbol{E}$ & Electric field \\
$\Phi$ & Electric potential \\
$\boldsymbol{i}$ & Current density vector \\
$\rho_{\mathrm{c}}$ & Resistivity of the equivalent CFRP material \\
$S_{\mathrm{e}}$ & Exchange surface \\
$S_{p}$ & Sample cross section \\
$\varepsilon$ & Material emissivity \\
$\sigma$ & Stefan-Boltzmann constant \\
$h$ & Coefficient of thermal convection \\
\hline
\end{tabular}

\section{Introduction}

The employment of carbon fibre reinforced polymer (CFRP) composite materials for aircraft fuselage structures is foreseen in the next future.

Aircraft fuselages may serve as "mass" and Faraday cages, therefore composite fuselage panels may be subjected to unwanted electric solicitations and current transit.

These electrical currents can be of three types:

(1) Electrical currents due to lightning strikes: currents of high magnitude (of the order of the $\mathrm{kA}$ ) which are applied for a very short lapse of time (ns or $\mu \mathrm{s}$ ).

(2) Ordinary electrical currents due to the electronic devices installed in the aircraft: currents of relatively low magnitude (of the order of few A, up to $10 \mathrm{~A}$ ) and relatively high frequency (up to $1 \mathrm{kHz}$ ).

(3) Electrical currents due to the accumulation of static electrical charges on the fuselage surfaces occurring mainly at the interfaces between the panels: these currents can be of relatively low magnitude, but they really depend on the geometry and the arrangement of the interfaces and on the panel-to-panel gaps.

Before integrating composite panels within the fuselage structure, the aircraft industry should develop technological solutions to avoid the direct impact of currents on composite materials/structures: this can be done, for instance, by protecting such materials/structures with thin layers made by electrically and thermally conductive materials.

In any case, a better understanding of ageing phenomena occurring in CFRP under the effect of coupled electromechanical solicitations is of paramount importance for a proper development of composite material fuselage structures.

The existing literature concerning the subject is not abundant.

DC and AC electrical currents are usually employed for damage assessment and health monitoring of composite materials and structures [1-6]. In this case, electrical resistance measurements - coupled to some material degradation model - are employed to assess damage onset and development within the composite structure: the injected currents are of very low magnitude (of the order of the $\mathrm{mA}$ ), therefore their direct impact on the composite material cannot be appreciated appropriately. Also some authors have employed electrical resistivity measurements for strain monitoring in composites laminates [7], cure monitoring and process-induced and fibre/matrix interface stress assessment $[8,9]$.

Other authors (for instance [10]) have studied the interaction effect between relatively high magnitude currents (several A) and electromagnetic fields on composite materials; these effects are not easy to understand and fall beyond the scope of the present paper.

Not much investigation has been carried out concerning the effects of intermediate currents (of the order of few A, up to $10 \mathrm{~A}$ ) on composite materials and structures. DC and AC currents of such order of magnitude may contribute to the development of ageing phenomena of electric nature (partially related to Joule heating), interact with other sources of ageing and decrease the durability of the material/structure.

In particular, such currents may promote Joule heating effects and lead to temperatures which may be high compared to the glass transition temperatures $\left(T_{\mathrm{g}}\right)$ of polymer matrix resins.

In a recent paper, Sierakowski et al. [11] have studied the heating effects of DC currents of different intensity (25 $\mathrm{A}$ and $50 \mathrm{~A}$ ) and duration (around 30 and $35 \mathrm{~min}$, respectively) on 32-ply AS4 carbon fiber polymer matrix composite plates. The current was injected through copper bars in contact with the composite plates and the surface temperature was measured by thermocouples at the centre of the plate. The measured temperatures were equal to around $36{ }^{\circ} \mathrm{C}$ for a unidirectional plate carrying a $25 \mathrm{~A}$ DC current and $70{ }^{\circ} \mathrm{C}$ for a cross-ply plate carrying a 50 A DC current. Employing a 3D numerical model the authors found that the temperature gradients within the composite plate (longitudinal and through the thickness) can be dramatic and considerable Joule heating can occur close to the copper/composite electric contact due to the contact resistance. In particular, the predicted temperatures at the contact locations were around $80^{\circ} \mathrm{C}$ for the unidirectional plate carrying $25 \mathrm{~A}$ DC current and around $295{ }^{\circ} \mathrm{C}$ (far above the glass transition temperature of the resin) for the cross-ply plate carrying 50 A DC current. However, the temperature close to contact interfaces was not measured and experimental evidence of temperature gradients across the plate was not provided.

The present paper focuses on the thermoelectric response of T300/914 $\left[(0 / 90)_{4}\right]_{s} \quad$ CFRP composites 
Table 1. Different types of surface electrodes.

\begin{tabular}{ll}
\hline Electrode type & Characteristics \\
\hline Prodec [12] & $\begin{array}{l}\text { "Industrial-like electrode" realised by copper } \\
\text { electrodepositing }(50-60 \mu \mathrm{m}) \text { on a chemically } \\
\text { polished (up to } 1 \mu \mathrm{m}) \text { composite surface edge }\end{array}$ \\
Tegma Frechin [13] & $\begin{array}{l}\text { "Industrial-like" electrode realised by copper } \\
\text { electrodepositing }(50-60 \mu \mathrm{m}) \text { on a chemically } \\
\text { polished (up to } 1 \mu \mathrm{m}) \text { composite surface edge } \\
\text { "Industrial-like" electrode realised by copper } \\
\text { electrodepositing (around } 50 \mu \mathrm{m} \text { ) on a thermically/dynamically } \\
\text { polished (around } 1 \mu \mathrm{m}) \text { composite surface edge }\end{array}$ \\
& $\begin{array}{l}\text { "Laboratoy" electrode realised by employing } \\
\text { Silver Paint }\end{array}$ \\
liquid silver deposited by hand & "Laboratoy" electrode realised by employing \\
Copper Coating & a solid (tape) copper coating deposited by hand \\
\hline
\end{tabular}

subjected to DC currents up to $8 \mathrm{~A}$ in view of developing experimental and modelling tools for the characterisation of the thermo-electro-mechanical behaviour of composite materials for aircraft applications.

In particular the authors foresee in the next future to carry out fatigue tests on electrified composite samples. In these tests couplings are such that thermal phenomena play a fundamental role, which must be assessed through a preliminary study.

The present study aims at:

- developing a way to inject currents into the samples preventing from dramatic Joule heating close to the contact zone, avoiding thermal spikes, thermal gradients and severe nonuniform temperature distribution;

- understanding the thermoelectric behaviour of composite materials for which coupled electro-mechanical fatigue tests are foreseen, measuring the full temperature field along the samples;

- interpreting the tests in the light of simple models which can be useful for parameter identification, parametric studies and design of further tests.

In the present paper DC currents up to $8 \mathrm{~A}$ are injected through the samples end sides by employing several different electrode techniques whose performances are assessed and compared. The transient and permanent temperatures fields promoted by the injected currents are experimentally measured on the external surfaces of the composite specimens by infrared thermography. Sample and electrode contact resistances are also measured for different values of the injected current.

The measured temperature fields are simulated numerically by a thermoelectric coupled model employing the ABAQUS ${ }^{\circledR}$ FE commercial code; temperatures can be also approximately calculated by a simple lumped parameter model discarding thermal conduction.

\section{Materials, experimental methods and testing}

It can be quite hard to inject currents of the order of the Ampere (A) into CFRP composite materials. In fact, carbon fibres are good conductors, characterised by low electrical resistivity values $\left(\rho_{\mathrm{f}} \approx 1.5 \times 10^{-2} \Omega . \mathrm{mm}\right)$; polymer resins behave as insulators when subjected to DC currents and exhibit very high resistivity values $\left(\rho_{\mathrm{m}} \approx\right.$ $\left.10^{16} \Omega . \mathrm{mm}\right)$. Usually currents of the order of the $\mathrm{mA}$ can be injected through the surfaces of a composite sample by employing silver paints without surface preparation; however for currents of the order of the A this solution is not effective. In fact, as soon as the current reaches the silver paint electrode the very high resistance of the thin surface resin layer promotes localised Joule heating which rises locally and sharply the temperature of the electrode. Therefore, the silver paint rapidly evaporates and the test is actually unfeasible.

For currents of the order of the A (or higher) the composite surface should be adequately prepared by mechanical and chemical polishing in order to dissolve the thin surface resin layer and put the fibres in direct contact with the electrode through which the current is injected.

Table 1 presents the different types of solutions employed in the present research for injecting the currents into the composites. A first class of solutions employs "industrial-like" techniques (Prodec, Tegma Frechin and Jetmetal) and consists in performing copper electrodepositing (with thickness of around $50 \mu \mathrm{m}$ ) on the chemically polished surface edges of the composite; a second class of solutions is represented by "laboratory-like" techniques, employing, for instance, silver paint or copper coating.

Besides some detail of the employed techniques, Table 1 presents also the website references of the industrial suppliers.

Figure 1 shows the geometry of the T300/914 $\left[(0 / 90)_{4}\right]_{s}$ CFRP samples (average dimension: $180 \mathrm{~mm} \times$ $15 \mathrm{~mm} \times 1.8 \mathrm{~mm}$ ) and some details of the surface electrode (Prodec-type electrodepositing).

Specimens are equipped with glass - epoxy tabs (average dimension: $65 \mathrm{~mm} \times 15 \mathrm{~mm} \times 0.85 \mathrm{~mm}$ ), whose function is double: to allow for mechanical testing and to provide electrical isolation of the sample from the testing device.

Figure 2 shows the experimental setup employed for thermoelectric testing: the specimen is aligned along the 


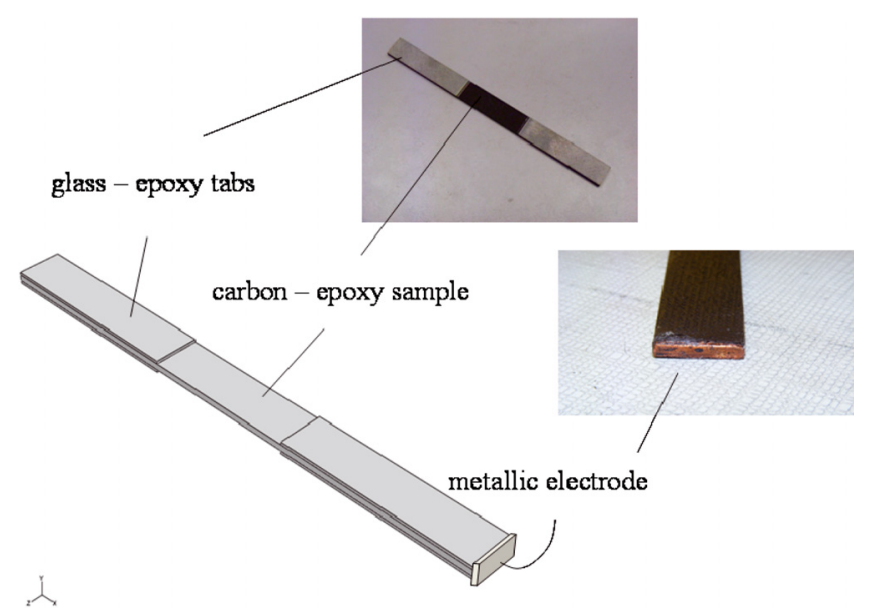

Fig. 1. Geometry of a sample and details of the metallic electrodes (Prodec copper electrodepositing).

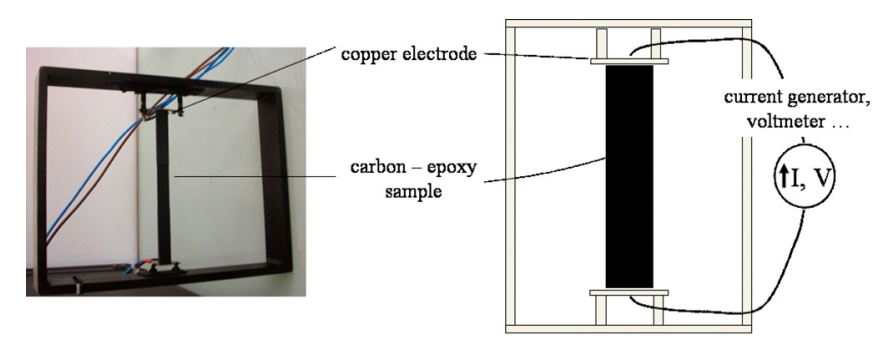

Fig. 2. Experimental setup.

vertical direction and each side of the sample (equipped with a surface electrode) is in contact with a copper electrode connected to a mechanical spring, which provides a small contact pressure between the electrodes.

The sample is aligned along the vertical direction as if it was placed into a fatigue test setup. In fact, we want to develop an experimental tool to perform simultaneous thermo-electro-mechanical tests to be carried out in a fatigue test setup. Therefore the temperature fields promoted by thermoelectric coupling have to be measured under the same test conditions.

DC currents up to $8 \mathrm{~A}$ were delivered by a DC generator connected to the sides of the composite specimen and a voltmeter was able to measure the electrical voltage.

Actually two methods can be employed for voltage measurements, see schematics in Figure 3. The so called two-probe method (Fig. 3a) measures the voltage between the sides of the DC generator, thus measuring the resistance of the composite sample, of the surface electrodes, of the electrical contact (depending on the contact pressure between the electrodes) and of the metallic wires leading the current to the specimen.

The so called four-probe method (Fig. 3b) measures the electrical voltage between the sides of the sample eliminating the resistance of the wires. This resistance depends on the wire configuration and material but is usually - very small. For instance, for a $2 \mathrm{~m}$ metallic wire, the electric resistance of the wire is less than $0.01 \Omega$.

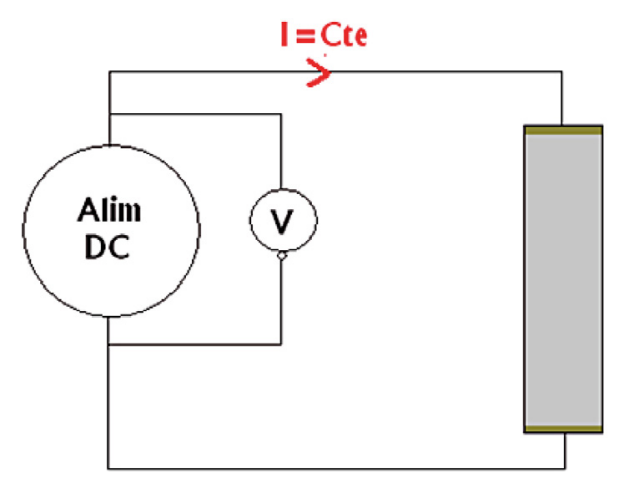

(a)

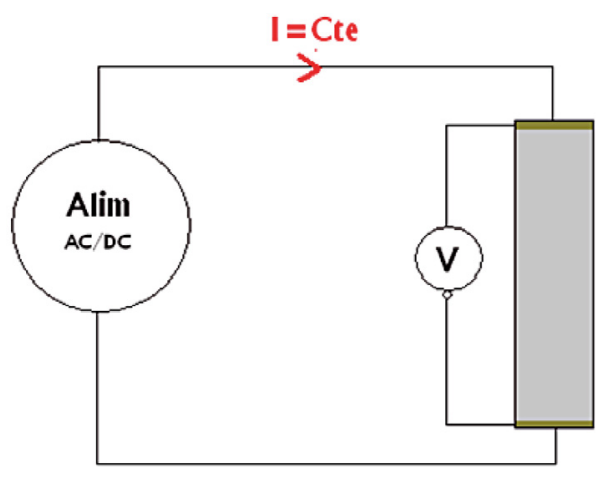

(b)

Fig. 3. Schematics of the adopted electric tension measurements. (a) Electrical scheme: two-probe method. (b) Electrical scheme: four-probe method.

The temperature was measured on the surface of the composite samples by a CEDIP 420M infrared thermography camera capable of measuring the temperature at each point of the composite surface with a precision lower that $1{ }^{\circ} \mathrm{C}$ and with a spatial resolution of 320 pixels $\times 256$ pixels (each square pixel having a surface of $0.3 \mathrm{~mm} \times 0.3 \mathrm{~mm}$ ). All the observed surfaces were painted in black in order to have the highest value of emissivity.

Data were post-processed by the ALTAIR software [15] in order to obtain explicitly the temperature profiles as a function of time at each point of the exposed surface.

The electrical voltage and the temperature were recorded continuously as a function of time.

\subsection{Measurements and analysis of the temperature field}

Figure 4a shows the temperature field contour measured by infrared thermography on the external surface of a specimen equipped with Prodec-type electrodes at $I=6 \mathrm{~A}$ (after around $900 \mathrm{~s}$ ) as given by the ALTAIR post-processing software for a sample subjected to the input current history illustrated in Figure 4b. The input 


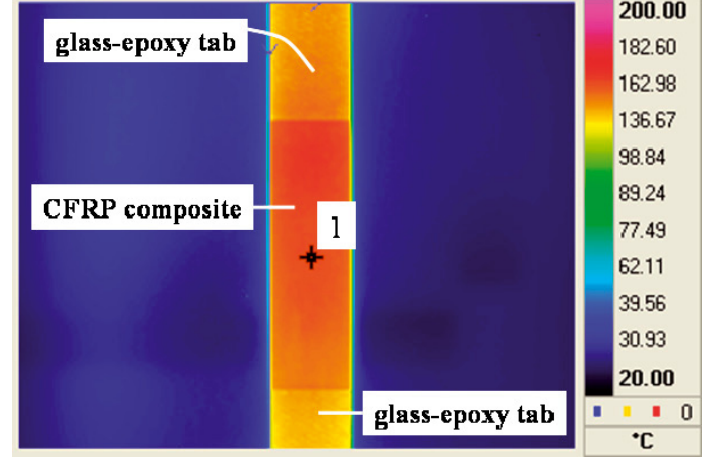

(a)

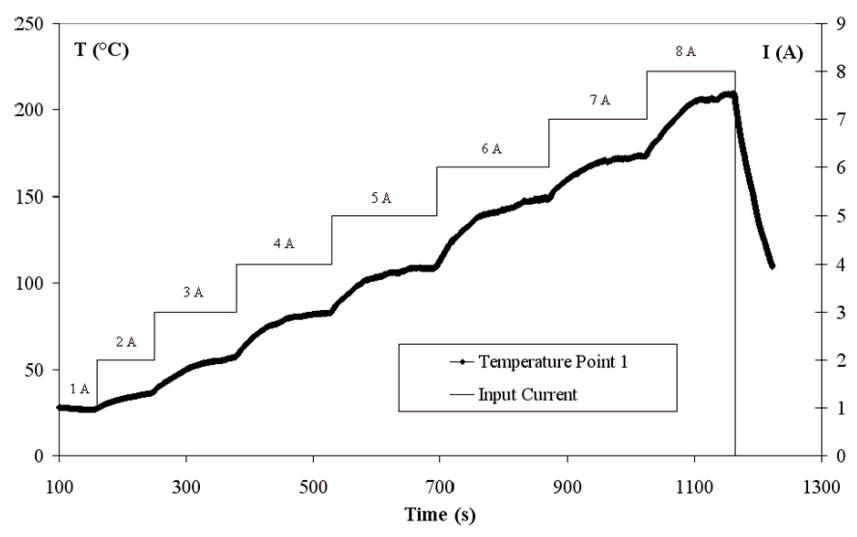

(b)

Fig. 4. (a) Temperature distribution (900 s) on the external sample surface as measured by infrared thermography (b) temperature evolution as a function of time of the central point (point 1) of the external surface. Sample equipped with Prodec-type electrodes.

current was increased from $0 \mathrm{~A}$ to $8 \mathrm{~A}$ by $1 \mathrm{~A}$ sudden steps. The duration of each step was not the same for each current value; the aim was to reach a thermal steady state for each value of input current. The average duration of a step was around $150 \mathrm{~s}$.

In Figure 4a the CFRP composite and the glass-epoxy tab zones can be clearly distinguished although some part of the glass-epoxy tabs falls outside the measured zone. After around $900 \mathrm{~s}$ (steady state at $6 \mathrm{~A}$ ) the temperature contour along the CFRP surface is fairly uniform (red contour) with an average value of around $155^{\circ} \mathrm{C}$. The temperature distribution along the glass-epoxy tab surface is also fairly uniform (yellow contour) with an average value of around $140{ }^{\circ} \mathrm{C}$, around $15{ }^{\circ} \mathrm{C}$ less than the CFRP surface.

Figure $4 \mathrm{~b}$ shows the temperature evolution of point 1 (Fig. 4a) as a function of time. It must be noted that point 1 is located at the centre of the sample.

Figure $4 \mathrm{~b}$ shows that - after the sudden application a DC current step - the temperature of point 1 initially increases and then tends towards a steady state. The time needed to reach such state is around $150 \mathrm{~s}$. Reaching a thermal steady state physically expresses the equilibrium between the heat power generated by the current (Joule effect) and the heat power exchanged with the environment by convection and radiation.

At $8 \mathrm{~A}$ the maximum temperature of point 1 is around $205{ }^{\circ} \mathrm{C}$, a value which is comparable to typical glass transition temperature $\left(T_{\mathrm{g}}\right)$ values of CFRP composites (between $160^{\circ} \mathrm{C}$ and $200^{\circ} \mathrm{C}$ ). Figure 5 helps visualising in a quite exhaustive manner the surface temperature field distribution along the sample, at different input current values (and different times, following the input current history in Fig. 4b).

Figure 5b illustrates the temperature values as a function of the $x$ coordinate (Fig. 5a) along three vertical lines (lines A, B and C in Fig. 5a) at input current values (and different times).

In Figures $5 \mathrm{~b}-\mathrm{e}$ the $x$ coordinate goes from $0 \mathrm{~mm}$ to $83 \mathrm{~mm}$; the coordinate $x=0 \mathrm{~mm}$ is around $43 \mathrm{~mm}$ far from the top Prodec electrode (and electrical contact), the coordinate $x=83 \mathrm{~mm}$ is around $55 \mathrm{~mm}$ far from the bottom Prodec electrode (and electrical contact). Line A is located along the centreline of the sample, lines B and $\mathrm{C}$ are located around $3 \mathrm{~mm}$ far from its sides.

In Figures 5b-e two dotted lines (at around $x=$ $22 \mathrm{~mm}$ and $x=73 \mathrm{~mm}$, respectively) separate the CFRP zone from the glass-epoxy tab zones.

Figures $5 \mathrm{c}$ and d detail the temperature distribution at two different input current values, $I=7 \mathrm{~A}(t=950 \mathrm{~s})$ and $I=8 \mathrm{~A}(t=1100 \mathrm{~s})$, respectively. Finally, Figure $5 \mathrm{e}$ illustrates the temperature distributions for $I=8 \mathrm{~A}$, at two different instants of time, $t=1035 \mathrm{~s}$ and $t=1150 \mathrm{~s}$, respectively.

Figures 5b-e show that the temperature gradient along the specimen's width is very small all through the test. Temperature values along lines A, B and C superpose at each time.

On the contrary, the temperature gradient along the sample length is not negligible; in both the CFRP and the glass-epoxy tab zones the temperature varies almost linearly along the length.

Table 2 resumes the maximum ( $\left.T_{\mathrm{MAX}}\right)$, the minimum $\left(T_{\mathrm{MIN}}\right)$ and the average $\left(T_{\mathrm{AVG}}\right)$ temperature along the CFRP external surface as a function of the input current (and time). It can be noted that the temperature difference between two points belonging to the CFRP surface can be as high as $30^{\circ} \mathrm{C}$, at $8 \mathrm{~A}(t=1150 \mathrm{~s})$. In the same table (last column) the values of the ratio ( $T_{\mathrm{MAX}}-$ $\left.T_{\mathrm{MIN}}\right) /\left(T_{\mathrm{AVG}}\right)(\%)$ are also reported. It can be noted that this ratio is equal to around $13 \%$ for each value of input current (and time).

Figures 5b-e show clearly that the surface temperature suffers from a sudden drop (around $20^{\circ} \mathrm{C}$ at $8 \mathrm{~A}$ ) at the interface between the CFRP zone and the glass-epoxy tabs.

Figure 6 shows the surface temperature of three distinct points located along the sample centreline (points 1 , 2 and 3 in Fig. 6a) as a function of time. Point 1 is located at the centre of the specimen; points 2 and 3 are located $21 \mathrm{~mm}$ and $37 \mathrm{~mm}$ far from point 1 , respectively. 


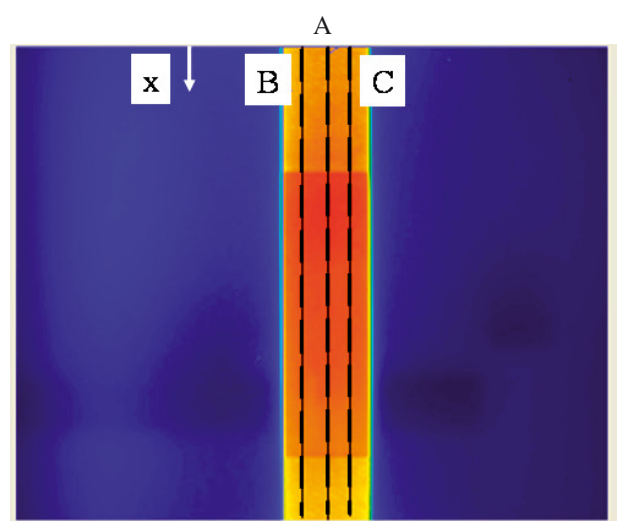

(a)

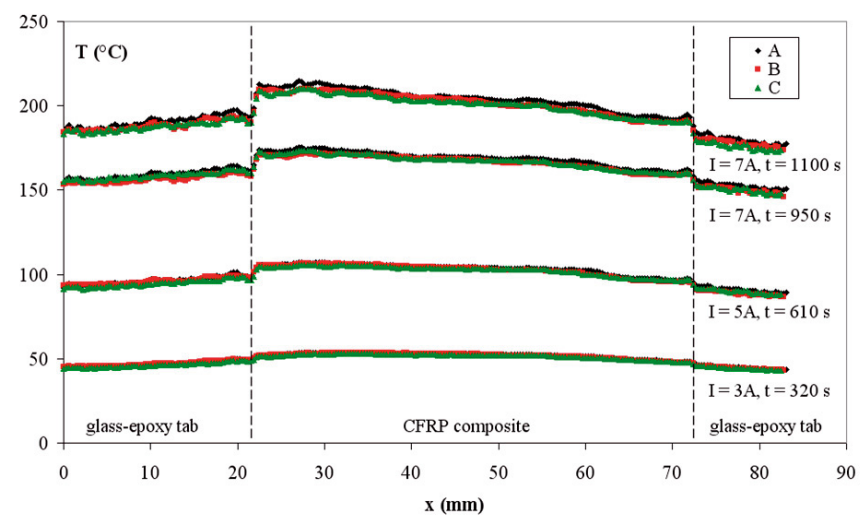

(b)

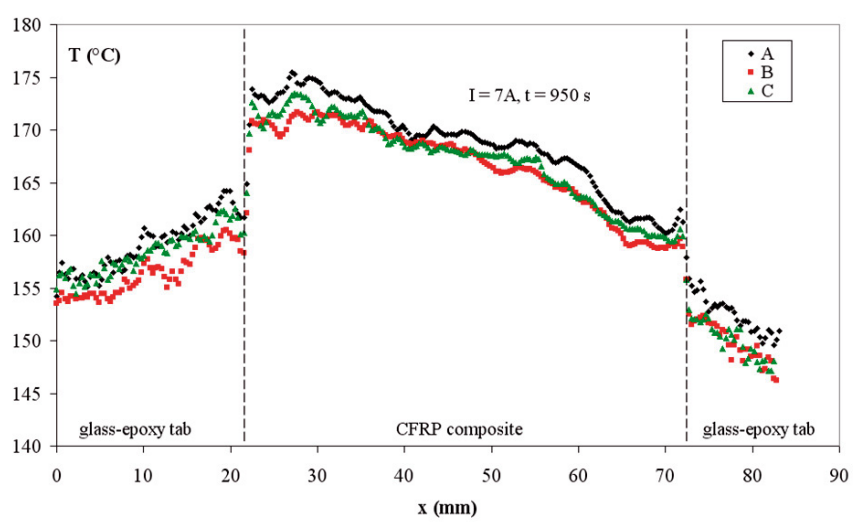

(c)

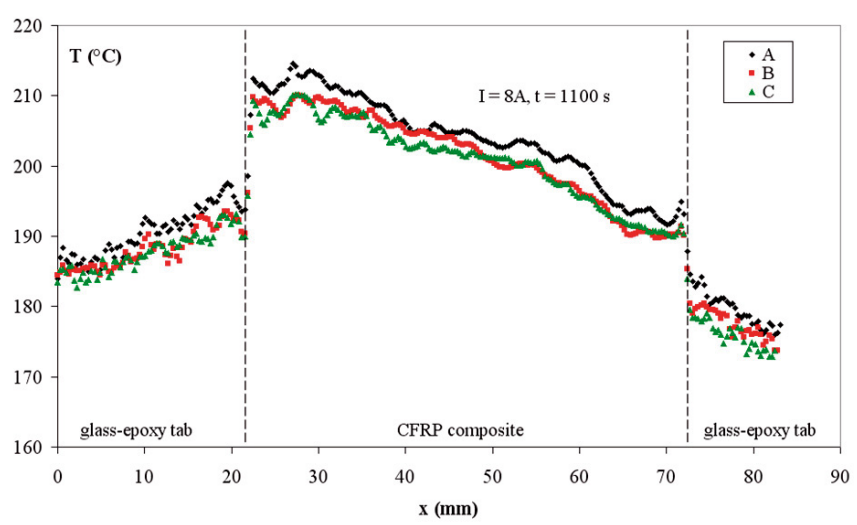

(d)

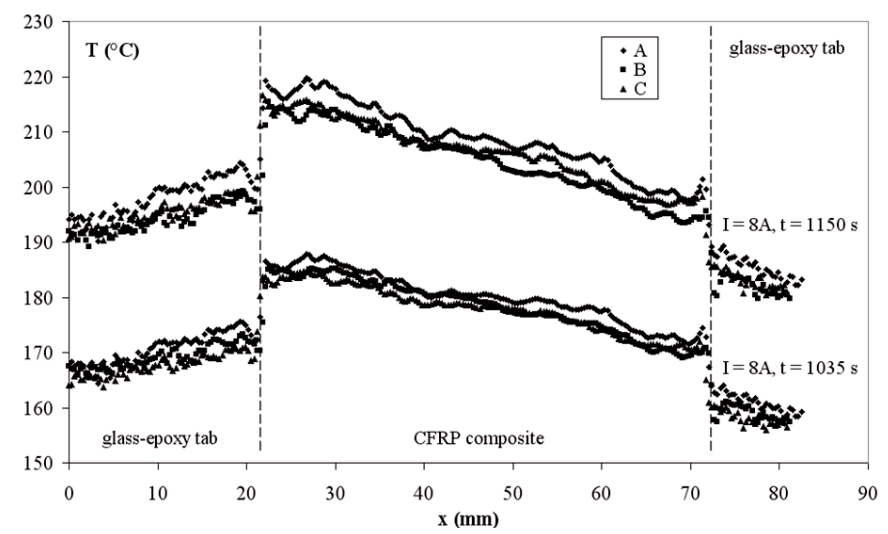

(e)

Fig. 5. (a) Illustration of the $x$ coordinate and three lines (A, B and C) along which the measured temperatures are extracted (b), (c), (d), (e), profiles of temperatures along the $x$ coordinate at different input current values (and times). Sample equipped with Prodec-type electrodes.

The temperature difference measured at each time between point 1 (in black) and 2 (in red) is representative of the temperature gradient existing along the CFRP zone. The temperature difference measured at each time between points 2 and 3 (in green) is representative of the temperature drop occurring at the interface between the CFRP and the glass-epoxy tab zones.
Figures 7 and 8 show the results of another test performed in order to check the surface temperature field close to the sample electrodes and to the electric contacts.

The input current history of this second test is not the same as the first test (Fig. 7b). The DC current is again raised up to $8 \mathrm{~A}$ through current steps. However the intensity of the current steps is not systematically 
Table 2. Maximum, minimum, average measured temperatures along the CFRP sample at different input currents (and times) and relative difference between the maximum and the minimum temperatures.

\begin{tabular}{lcccc}
\hline & $T_{\mathrm{MAX}}\left({ }^{\circ} \mathrm{C}\right)$ & $T_{\mathrm{MIN}}\left({ }^{\circ} \mathrm{C}\right)$ & $T_{\mathrm{AVG}}\left({ }^{\circ} \mathrm{C}\right)$ & $\left(\frac{T_{\mathrm{MAX}}-T_{\mathrm{MIN}}}{T_{\mathrm{AVG}}}\right) \%$ \\
\hline $\begin{array}{l}I=3 \mathrm{~A} \\
(t=320 \mathrm{~s})\end{array}$ & 53.6 & 46.5 & 51.9 & 13.6 \\
$\begin{array}{l}I=5 \mathrm{~A} \\
(t=610 \mathrm{~s})\end{array}$ & 107.2 & 93.6 & 103.1 & 13.2 \\
$\begin{array}{l}I=7 \mathrm{~A} \\
(t=950 \mathrm{~s})\end{array}$ & 175.4 & 155.8 & 168.6 & 11.6 \\
$\begin{array}{l}I=8 \mathrm{~A} \\
(t=1035 \mathrm{~s})\end{array}$ & 187.9 & 162.7 & 179.9 & 13.9 \\
$\begin{array}{l}I=8 \mathrm{~A} \\
(t=1080 \mathrm{~s})\end{array}$ & 208.5 & 176 & 198.3 & 16.3 \\
$\begin{array}{l}I=8 \mathrm{~A} \\
(t=1100 \mathrm{~s})\end{array}$ & 214.6 & 184.5 & 203.8 & 14.7 \\
$\begin{array}{l}I=8 \mathrm{~A} \\
(t=1150 \mathrm{~s})\end{array}$ & 219.8 & 187.6 & 208.5 & 15.4 \\
\hline
\end{tabular}

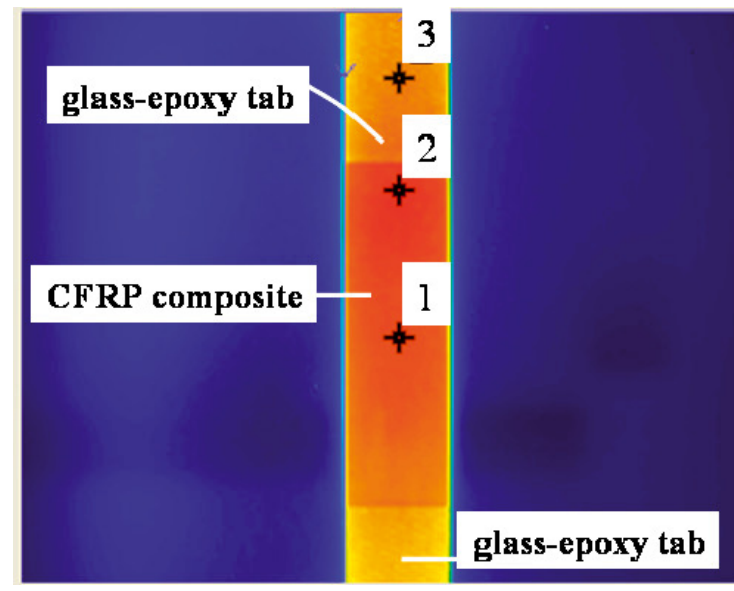

(a)

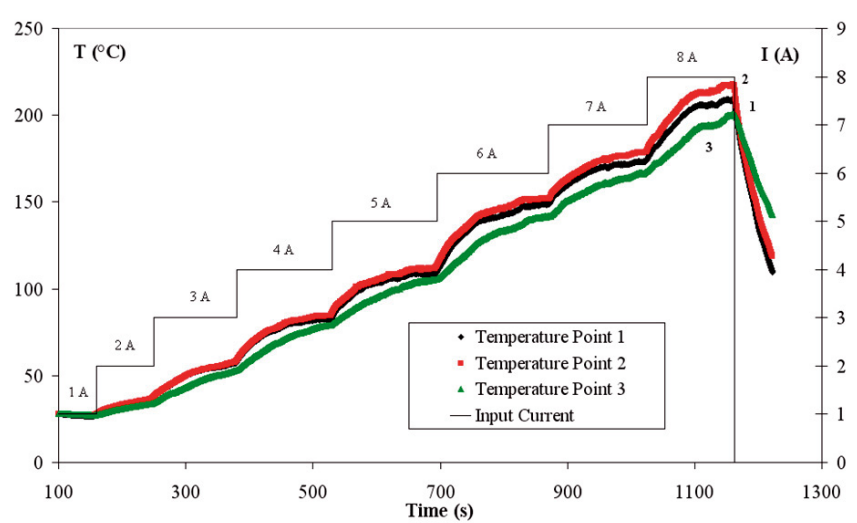

(b)

Fig. 6. (a) Illustration of three distinct points (1,2 and 3$)$ at which the measured temperatures are extracted (b) temperature evolution at points 1,2 and 3 as a function of time and input current history. Sample equipped with Prodec-type electrodes.

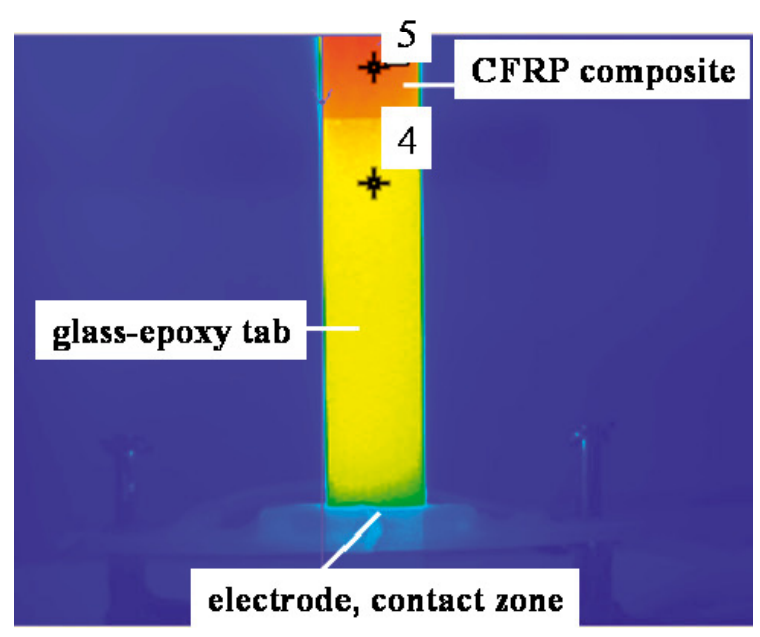

(a)

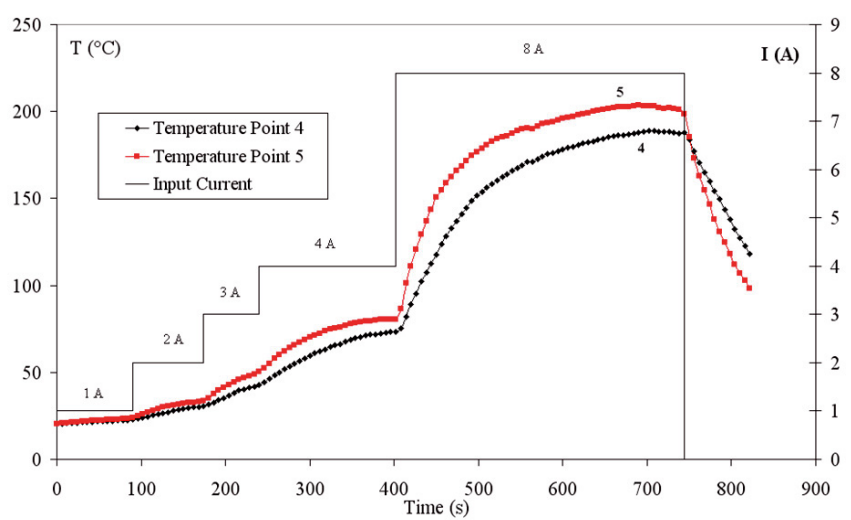

(b)

Fig. 7. (a) Illustration of two distinct points (1 and 2) at which the measured temperatures are extracted (b) temperature evolution at points 1 and 2 as a function of time and input current history. Sample equipped with Prodec-type electrodes. 
the same. For instance, at around $t=410 \mathrm{~s}$, the current is suddenly raised from $4 \mathrm{~A}$ up to $8 \mathrm{~A}$. This is done in order to check the effects of a consistent temperature sudden change (comparatively to the first test) on the sample response.

In Figure 7a the CFRP and the glass-epoxy tab zones can be clearly distinguished; the contact zone represents the location in which the electrodes are in contact with a copper electrode connected to the DC generator through a wire.

Figure $7 \mathrm{~b}$ shows the temperature of two distinct points located along the sample centreline and close to the electrodes and the electric contacts (point 4 and point 5, see Fig. 7a) as a function of time. Point 4 and point 5 are around $49 \mathrm{~mm}$ and $66 \mathrm{~mm}$ far from the electrode (Fig. 7a); point 4 on the glass-epoxy tab surface, point 5 on the CFRP surface.

Figure $7 \mathrm{~b}$ shows that the temperature measured - at each time - at point 4 is sensibly different from that measured at point 5: at $8 \mathrm{~A}$, this difference is around $20{ }^{\circ} \mathrm{C}$. Again this difference is representative both of a temperature gradient existing along the CFRP zone and of the temperature drop occurring at the interface between the CFRP and the glass-epoxy tab zones.

As in Figure 5, Figures 8b-d illustrate the temperature values as a function of the $x$ coordinate (Fig. 8a) along three vertical lines (lines A, B and C in Fig. 8a) at different input current values (and times). In this case the $x$ coordinate goes from $0 \mathrm{~mm}$ to around $71 \mathrm{~mm}$. The coordinate $x=71 \mathrm{~mm}$ is located almost exactly in correspondence with the electrode and the electric contact. Again the dotted line in Figures $8 \mathrm{~b}-\mathrm{d}$ separates the CFRP zone from the glass-epoxy tab zone.

Figures $8 \mathrm{~b}-\mathrm{d}$ show the existence of a significant temperature gradient along the length of the specimen. This gradient is particularly marked close to the electrodes and electric contacts. At $I=8 \mathrm{~A}(t=600 \mathrm{~s})$, the maximum temperature difference between two points of the glassepoxy tab surface is around $60{ }^{\circ} \mathrm{C}$.

However, no localised heating is observed close to the electrode and on the electric contacts. On the contrary, in the proximity of the electrodes the measured temperatures are consistently lower than those measured close to the centre. Again, we remark that the gradient along the sample width is negligible.

Similar temperature measurements have been carried out on at least three samples made by the same composite materials and equipped with the same electrode.

This assures the reproducibility of the test and the consistency of the temperature fields measured on the surface of the composite specimens.

In particular - for all the performed tests - the qualitative and quantitative shape and intensity of the measured temperature gradients are in agreement with the results presented in Table 2.

The relative difference between the maximum and the minimum temperature along the CFRP sample is not higher than around $15 \%$ for all values of input DC current.

\subsection{Voltage and resistance measurements}

Figure 9 shows the measured voltage (4-probe method) as a function of the delivered DC current on a specimen equipped with Prodec-type electrodes.

The voltage values reported in Figure 9 - for each value of current - correspond to a stabilized thermal state, in which the sample temperature field has reached a stationary state.

It is noted that, all along the full range of measured temperatures, the Ohm's law (linearity between applied DC current and measured voltage) is verified, at least in the temperature range explored in the present research. The sample resistance - identified by linear regression on the curve in Figure 9 - is around $0.44 \Omega$. As a general remark it is noted that this value of resistance is relatively small and produces low values of the dissipated power (by Joule effect), around 40-50 W, for the DC currents employed in the present study.

As mentioned earlier, the resistance thus measured takes into account the contribution of the surface electrodes (for the Prodec-type electrodes it represents the resistance of the copper electrodepositing) and of the electrical contact, that is:

$$
R_{\mathrm{m}}=R_{\mathrm{s}}+R_{\mathrm{e}}+R_{\mathrm{c}}
$$

in which $R_{\mathrm{m}}$ is the measured resistance, $R_{\mathrm{s}}$ the sample resistance, $R_{\mathrm{e}}$ the electrode resistance and $R_{\mathrm{c}}$ the contact resistance.

Figure 10 shows the experimental electrical resistance (measured by 4-probe voltage measurements) measured at room temperature as a function of the sample length $L_{x}$. These tests allow identifying the measured resistance as:

$$
R_{\mathrm{m}}=0.002 L_{x}+0.08(\Omega)
$$

The measured sample resistance, $R_{\mathrm{m}}$, can be thus written as the sum of a term depending linearly on the total length of the specimen, $L_{x}$, and a constant term representing the resistance of the surface electrodes and of the electrical contact. Then by comparing Equations (1) and (2), we can write:

$$
R_{\mathrm{s}}=0.002 L_{x}(\Omega) \quad R_{\mathrm{e}}+R_{\mathrm{c}}=0.08(\Omega)
$$

Under the hypothesis that the DC current circulates only along the $0^{\circ}$ plies of the composite, the sample resistance, $R_{\mathrm{s}}$, can be expressed as:

$$
R_{\mathrm{s}}=\frac{\rho_{\mathrm{f}} L_{x}}{V_{\mathrm{f}} L_{y} e_{0}}
$$

in which $\rho_{\mathrm{f}}$ and $V_{\mathrm{f}}$ are the fibre resistivity and volume fraction, respectively, $L_{x}$ and $L_{y}$ are the sample length and width, respectively, and $e_{0}$ is the total thickness of the $0^{\circ}$ plies. For the specimens considered in the present study, in which $V_{\mathrm{f}}=0.6, L_{y}=15 \mathrm{~mm}$ and $e_{0}=1 \mathrm{~mm}$, by comparing Equations (3a) and (4) the calculated value of $\rho_{\mathrm{f}}$ is equal to $1.8 \times 10^{-2} \Omega$.mm which is very close to that given in the Torayca T300 carbon fibre datasheet 


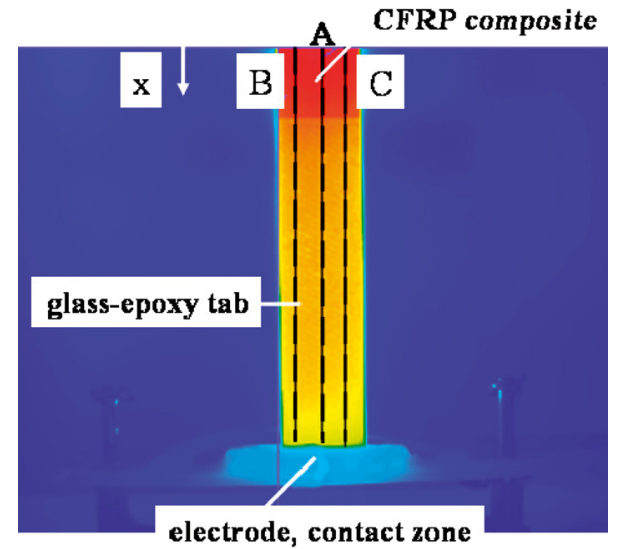

(a)

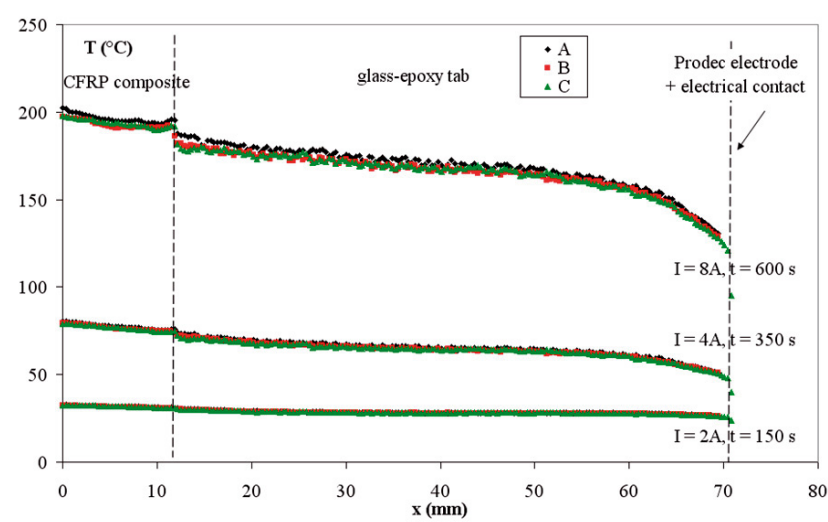

(b)

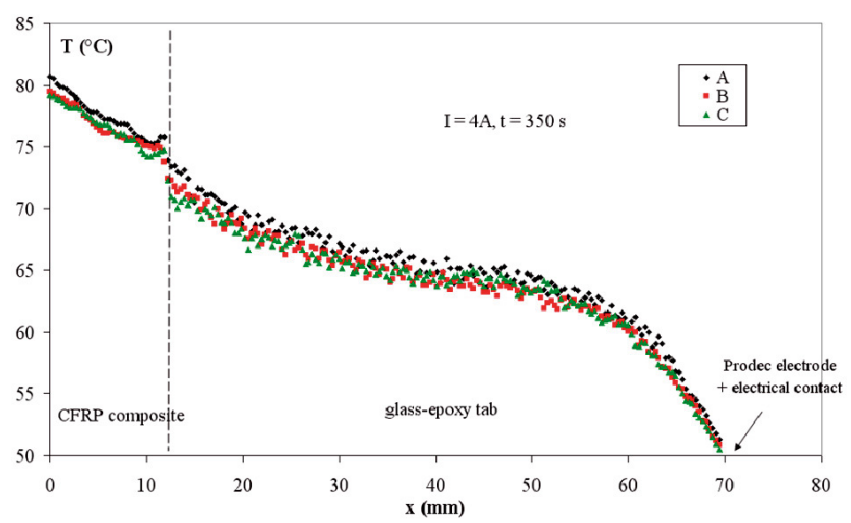

(c)

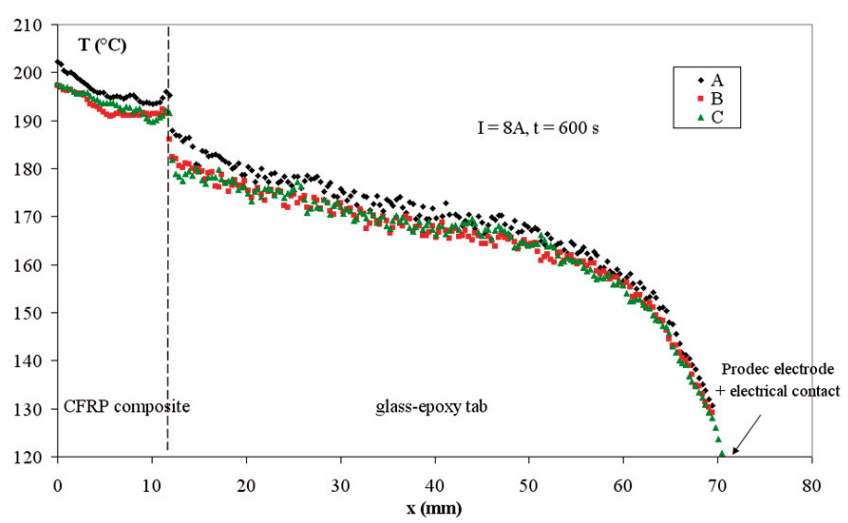

(d)

Fig. 8. (a) Illustration of the $x$ coordinate and three lines (A, B and C) along which the measured temperatures are extracted (b), (c), (d), profiles of temperatures along the $x$ coordinate at different input current values (and times). Sample equipped with Prodec-type electrodes.

(which is $1.7 \times 10^{-2} \Omega . \mathrm{mm}$, see [17]). Considering some uncertainty in the measurement of $e_{0}\left(e_{0}=0.9 \div 1 \mathrm{~mm}\right)$ the value of $\rho_{\mathrm{f}}$ is approximately bounded by the values $1.6 \times 10^{-2} \Omega$.mm and $1.8 \times 10^{-2} \Omega . m m$, respectively (and, conversely, the electric conductivity $\sigma_{\mathrm{f}}$ values are bounded between 55.5 S.mm and 62.5 S.mm, respectively).

This estimation is satisfactorily, confirms the hypothesis that current flows only along the fibres of the $0^{\circ}$ plies along which the current is applied, is consistent with Equation (4) and shows that this equation is appropriate for calculating the global resistance of any composite sample.

\subsection{Behaviour of other sample electrodes}

The behaviour of specimens equipped with Frechintype and JetMetal-type electrodes is not different from that of samples with Prodec-type electrodes, both qualitatively and quantitatively.

On the other hand, silver paint and copper coating ("laboratory-type") solutions are not much satisfactory.

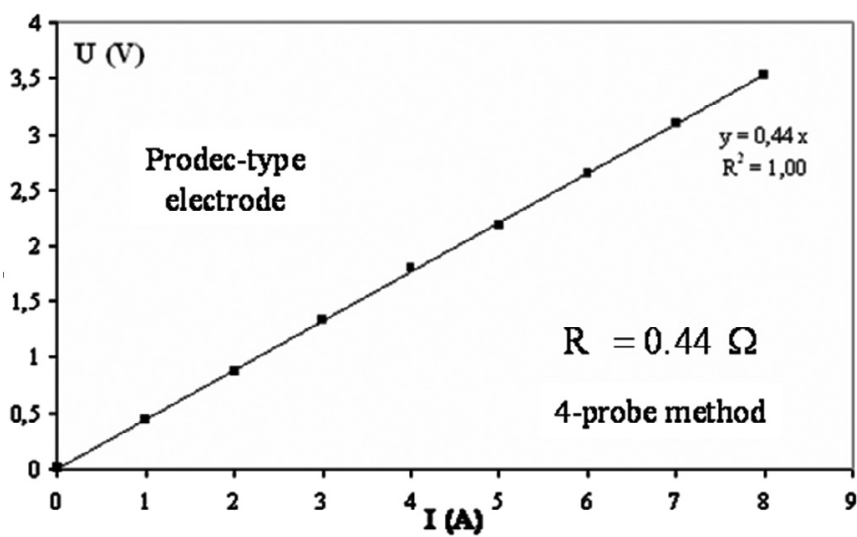

Fig. 9. Measured electric tension as a function of the injected current in a sample equipped with Prodec-type electrodes.

The global resistance of a sample equipped with silver paint electrodes was close to $1 \Omega$, a relatively high value, and the silver paint evaporated at $4 \mathrm{~A}$, the surface temperatures being of the order of $200{ }^{\circ} \mathrm{C}$. 
Table 3. Performance of the different types of surface electrodes.

\begin{tabular}{lccccc}
\hline & Prodec & Fréchin & JetMetal & Silver Paint & Copper Coating \\
\hline Maximum injected & 8 & 8 & 8 & 4 & 1 \\
DC current (A) & 215 & 194 & 190 & $X$ & $X$ \\
$T_{\max }\left({ }^{\circ} \mathrm{C}\right)$ & 0.44 & 0.44 & 0.40 & 0.95 & 40 \\
$R(\Omega)$ & NO & NO & NO & YES & YES \\
$\begin{array}{l}\text { Thermal heating close to } \\
\text { the electrode }\end{array}$ & & & & Unfeasible \\
Performances, observations & Satisfactory & Satisfactory & Satisfactory & Contact loss at 4 A &
\end{tabular}

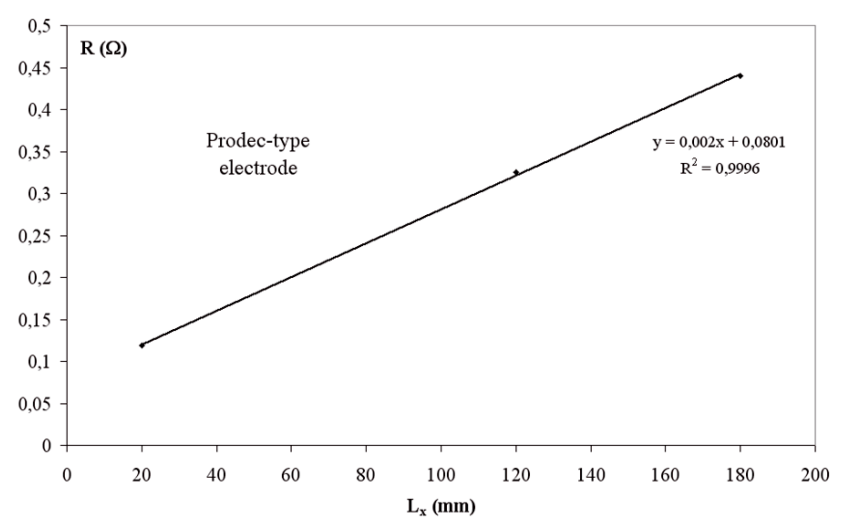

Fig. 10. Measured resistance as a function of the sample length (Prodec-type electrodes).

The global resistance of a specimen equipped with a copper coating was close to $40 \Omega$, the local temperature in the proximity of the surface electrode was very high for very low values of the applied current and the test was then unfeasible.

Table 3 summarises the performances of all the different surface electrodes.

The performances of all the "industrial" electrodes are very close and all satisfactory. Such solutions should be employed if a current of the order of the A had to be injected in a composite sample. In fact such solutions do not produce localised heating close to the electrodes nor along the electrical contact zone.

\subsection{General remarks on the experimental section}

Some partial conclusions can be drawn concerning the experimental activity:

- "industrial" electrodes have to be chosen if DC input current values of the order of the Ampere are injected into the composite samples, independently of the sample geometry. In fact, by adopting such electrodes, localised heating close to the electric contacts is prevented and the sample temperature is fairly uniform along the CFRP surface. A fairly homogeneous temperature field is needed in view of complex thermoelectro-mechanical tests where all the involved fields should be kept as uniform as possible;
- although the temperature field is fairly uniform along the specimen an accurate measurement of the temperature field shows the existence of a temperature gradient along the longitudinal sample direction and clearly visible in the CFRP and in the glass-epoxy tab zones. This phenomenon is not easy to explain. Some heat may flow out from the sample through the electric contacts due to the thermal inertia of the frame of the experimental setup (illustrated in Fig. 2). Then, some nonuniform convective phenomena may take place along the specimen surface since hot air tends to flow from the bottom to the top of the sample. These phenomena may partly explain the shape of the temperature gradients observed in Figures 5 and 8. Better insight could be gained by a detailed study of the air flow around the specimen. The present paper does not enter into such detail. On the other hand, since the temperature at the heart of the sample is not known it is not possible to say - for the moment - whether such gradients represent a surface phenomenon or involve the whole specimen. It is useful to remark that both phenomena are expected to take place in a sample fixed along the vertical direction in a fatigue test setup;

- fibres electrical resistivity and conductivity can be easily identified by voltage (thus resistance) measurements on composite samples. The identified values are almost insensitive to input current values (and temperatures) at least for the temperature range explored in the present paper.

\section{Modelling of the thermoelectric coupling}

Two coupled thermoelectric models have been employed for the interpretation and the simulation of the experiments.

The first model employs the ABAQUS ${ }^{\circledR}$ commercial finite element code and is able to simulate the transient behaviour of the sample, which can be complex depending on the geometry of the specimen and on the input current history.

The second model is based on a simple balance between the Joule dissipated power and the power exchanged with the environment by radiation and convection; it discards internal conduction within the sample and is able to catch the average equilibrium temperature of the CFRP specimen. This second model can be useful to assess the qualitative features of the thermoelectric 
Table 4. Material properties employed for the ABAQUS ${ }^{\circledR}$ simulations.

\begin{tabular}{|c|c|c|c|c|c|}
\hline & & $\begin{array}{c}\text { Density } \\
\rho\left(\mathrm{kg} \cdot \mathrm{m}^{-3}\right)\end{array}$ & $\begin{array}{c}\text { Thermal conductvity } \\
\lambda\left(\mathrm{W} \cdot \mathrm{m}^{-1} \cdot{ }^{\circ} \mathrm{C}^{-1}\right)\end{array}$ & $\begin{array}{l}\text { Electrical conductity } \\
\sigma \sigma\left(\mathrm{S} \mathrm{m}^{-1}\right)\end{array}$ & $\begin{array}{c}\text { Specific heat } \\
c\left(\mathrm{~J}_{\mathrm{kg}}{ }^{-1} \cdot{ }^{\circ} \mathrm{C}^{-1}\right)\end{array}$ \\
\hline \multirow{5}{*}{$\begin{array}{l}\text { CFRP } \\
\text { material }\end{array}$} & T300 [17] & 1700 & 10 & & 795 \\
\hline & carbon fibres & & & & \\
\hline & $914[18]$ & 1290 & 0.25 & & 1200 \\
\hline & resin & & & & \\
\hline & composite & 1530 & 6.1 & $18.5 \times 10^{3}$ & 957 \\
\hline \multicolumn{2}{|c|}{$\begin{array}{c}\text { glass-epoxy tab } \\
\text { material }\end{array}$} & 2076 & 0.25 & $10^{-10}$ & 1200 \\
\hline
\end{tabular}

behaviour of composite samples, to predict rapidly their temperatures, to perform parametric studies and to design thermoelectric tests.

We want both models to be simple, that is, based on straight hypotheses and characterised by the smallest number of parameters.

\subsection{Numerical ABAQUS model}

In order to simulate the spatial temperature distribution along the composite sample in the transient state, as a function of time, a coupled numerical thermoelectric model has been employed.

This model uses the ABAQUS ${ }^{\circledR}$ FE numerical solver [8], by employing 8-node linear hexahedral DC3D8E coupled thermoelectric bricks.

The numerical module solves simultaneously the following thermoelectric equations:

$$
\begin{aligned}
\rho c_{v} \frac{\partial T}{\partial t} & =\boldsymbol{\nabla} \cdot(\lambda \nabla T) r i^{2} \\
\boldsymbol{E} & =r \boldsymbol{i}=-\boldsymbol{\nabla} \Phi
\end{aligned}
$$

which express the simplest form of thermoelectric coupling. In fact in Equation (5) the only thermoelectric coupling term is represented by the dissipation Joule heating term, $r i^{2}$, while Equation (6) represents simply the Ohm's law written at a local scale.

In Equations (5) and (6), $\rho$ is the local density of the material, $T$ the local temperature, $c_{v}$ the specific heat of the material $\left(c_{v}=\partial u / \partial T\right.$, in which $u$ is the internal energy per unit mass), $\lambda$ is the material heat conductivity, $r$ a coefficient of electrical resistivity, $\boldsymbol{i}$ the current density vector (whose $i$ is the magnitude); $\boldsymbol{E}$ is the electric field and $\Phi$ the electric potential.

It should be noted that by Equation (6), locally, the electric field is related to the electric potential, $\Phi$, by a relation which is classical in electrostatics.

The CFRP and the glass-epoxy tab materials are modelled by equivalent homogeneous isotropic materials (without modelling in detail each physical ply).
The material properties of the equivalent isotropic CFRP T300/914 material have been determined by the simplest rule of mixtures:

$$
X_{\mathrm{c}}=X_{\mathrm{f}} V_{\mathrm{f}}+X_{\mathrm{m}}\left(1-V_{\mathrm{f}}\right)
$$

in which $X_{\mathrm{c}}$ is the property of the composite, $X_{\mathrm{f}}$ is the property of the fibre, $X_{\mathrm{m}}$ is the property of the matrix and $V_{\mathrm{f}}$ is the fibre volume fraction, by employing the material properties of the basic constituents reported in Table 4 and taken from the supplier datasheet $[17,18]$.

The value of resistivity of the equivalent CFRP material, $\rho_{\mathrm{c}}$, has been determined by the measured sample resistance $\left(R_{\mathrm{S}}=0.36 \Omega\right)$ and by employing the relation:

$$
R_{\mathrm{s}}=\frac{\rho_{\mathrm{c}} L_{x}}{L_{y} e}
$$

in which $L_{x}, L_{y}$ and $e$ are the (measured) dimensions of the CFRP specimen.

Since the exact properties of the glass-epoxy tabs are not known, some properties found in the literature [19] typical for glass-epoxy composite materials - have been employed.

Equations (5) and (6) must be solved with the appropriate boundary conditions, for both thermal and electric fields.

In the present study, the values of the electric potential are specified as constant on the electrode surfaces and are chosen in such a way that the electric potential differential between the two surfaces produces the wanted electric field (current) along the composite sample.

The radiation and convection heat fluxes are specified on the external surfaces. Figure 11 shows schematics of the sample model for ABAQUS ${ }^{\circledR}$ numerical calculations and the related boundary conditions. 74400 elements (88 443 nodes) were used for numerical simulations. During the transient simulation the time increment was left to be chosen automatically by the solver. However - for each step - the initial time increment was set to $0.01 \mathrm{~s}$ in order to simulate accurately the first phases of the transient regime.

Table 5 presents the numerical values of the coefficients employed for the simulation of convection and radiation exchanges. The value $h=5 \mathrm{~W} \cdot \mathrm{m}^{-2} \cdot{ }^{\circ} \mathrm{C}^{-1}$ - taken 
Table 5. Coefficients for the simulation of the convection and radiation exchanges (ABAQUS ${ }^{\circledR}$ simulations).

\begin{tabular}{ccc}
\hline Radiation & Surface emissivity & Sink temperature \\
exchange & $\varepsilon=0.99$ & $T_{0}=20{ }^{\circ} \mathrm{C}$ \\
\hline Convection & surface convection & sink temperature \\
exchange & coefficient & $T_{0}=20{ }^{\circ} \mathrm{C}$ \\
& $h=5 \mathrm{~W} \cdot \mathrm{m}^{-2} \cdot{ }^{\circ} \mathrm{C}^{-1}$ & \\
\hline
\end{tabular}

radiation and convection thermal flux specified on the exchange surfaces of the sample

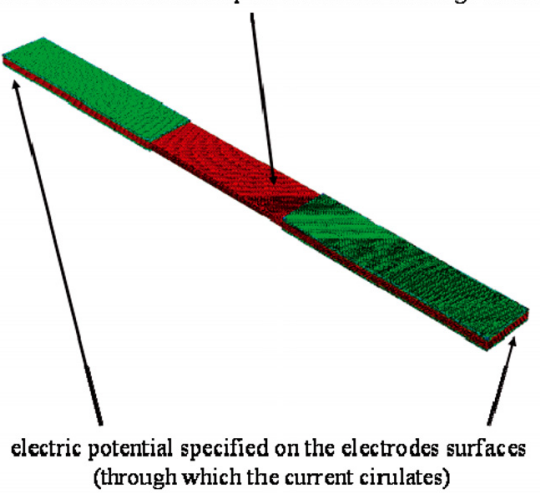

Fig. 11. Schematic illustration of the ABAQUS ${ }^{\circledR}$ model (as given by the ABAQUS ${ }^{\circledR}$ CAE viewer) and the employed thermal and electrical boundary conditions.

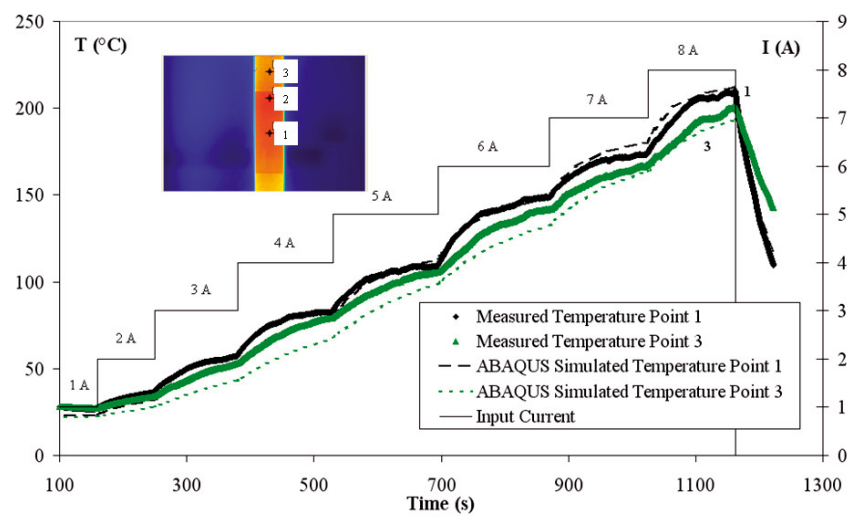

Fig. 12. Measured and ABAQUS ${ }^{\circledR}$ simulated temperature at points 1 and 3 (Fig. 6a), as a function of time (and different input current values).

constant and uniform along the whole sample surface - is typical for convection exchanges with free air at rest.

Figure 12 presents the temperature evolution of points 1 (at the centre of the CFRP sample) and 3 (located on the glass-epoxy tabs) as measured experimentally and simulated by the ABAQUS ${ }^{\circledR}$ model. The agreement is fairly good for each value of input current, in particular for point 1. The slight discrepancy observed for point 3 could be related - among other - to the lack of knowledge about the exact material properties of the glass-epoxy tabs.

Finally Figure 13 shows a comparison between the numerical simulations and the experimental measurements illustrated in Figure 5, for $I=8 \mathrm{~A}$, at two distinct
Table 6. Average measured and average simulated ABAQUS ${ }^{\circledR}$ temperatures along the CFRP sample at different input current values (and times) and relative difference.

\begin{tabular}{lccc}
\hline & $T_{\mathrm{AVG}}\left({ }^{\circ} \mathrm{C}\right)$ & $T_{\mathrm{ABA}}\left({ }^{\circ} \mathrm{C}\right)$ & \\
\hline $\begin{array}{l}I=3 \mathrm{~A} \\
(t=320 \mathrm{~s})\end{array}$ & 51.9 & 47 & -9.4 \\
$I=5 \mathrm{~A}$ & 103.1 & 104 & 0.8 \\
$\begin{array}{l}t=610 \mathrm{~s}) \\
I=7 \mathrm{~A}\end{array}$ & 168.6 & 168 & -0.3 \\
$\begin{array}{l}t=950 \mathrm{~s}) \\
I=8 \mathrm{~A}\end{array}$ & 179.9 & 187 & 3.9 \\
$(t=1035 \mathrm{~s})$ & & & \\
$\begin{array}{l}I=8 \mathrm{~A} \\
(t=1080 \mathrm{~s})\end{array}$ & 198.3 & 200 & 0.8 \\
$\begin{array}{l}I=8 \mathrm{~A} \\
(t=1100 \mathrm{~s})\end{array}$ & 203.8 & 207 & 1.5 \\
$\begin{array}{l}I=8 \mathrm{~A} \\
(t=1150 \mathrm{~s})\end{array}$ & 208.5 & 210 & 0.7 \\
\hline
\end{tabular}

instants of time. Table 6 collects the average experimental $\left(T_{\mathrm{AVG}}\right)$ and ABAQUS ${ }^{\circledR}$ average $\left(T_{\mathrm{ABA}}\right)$ temperature values along the CFRP for different input current values and at different times, as well as their their relative difference.

Despite the model is not able to reproduce fully the complex temperature gradient along the sample length, the comparison seems satisfactory. In particular the model captures well - at each time of the transient regime - the average temperature of the CFRP specimen and is able to catch the temperature drop at the interface between the CFRP and the glass-epoxy tab zones.

It should be kept in mind that the model works with spatially uniform and time constant material properties. Also the thermal boundary conditions are uniform and constant.

Therefore the model is not able to take into account for instance - complex convective interaction between the specimen and the external environment, which could explain the existence of surface temperature gradients along the sample longitudinal direction.

\subsection{Simplified model}

As mentioned in the experimental section the setting of a thermal steady state expresses the equilibrium between the heat power generated by the current (Joule) effect and the heat power exchanged with the environment by convection and radiation.

In this case we can attempt simulating the temperature of the CFRP by the following simple formula:

$$
R_{\mathrm{s}} i^{2}=\varepsilon \sigma \frac{S_{\mathrm{e}}}{S_{\mathrm{p}}^{2}}\left(T^{4}-T_{0}^{4}\right)+h \quad \frac{S_{\mathrm{e}}}{S_{\mathrm{p}}^{2}}\left(T-T_{0}\right)
$$

which, in fact, expresses the equilibrium between the dissipated Joule heat power (left hand side) and the heat power exchanged with the environment by radiation and convection (right hand side). 


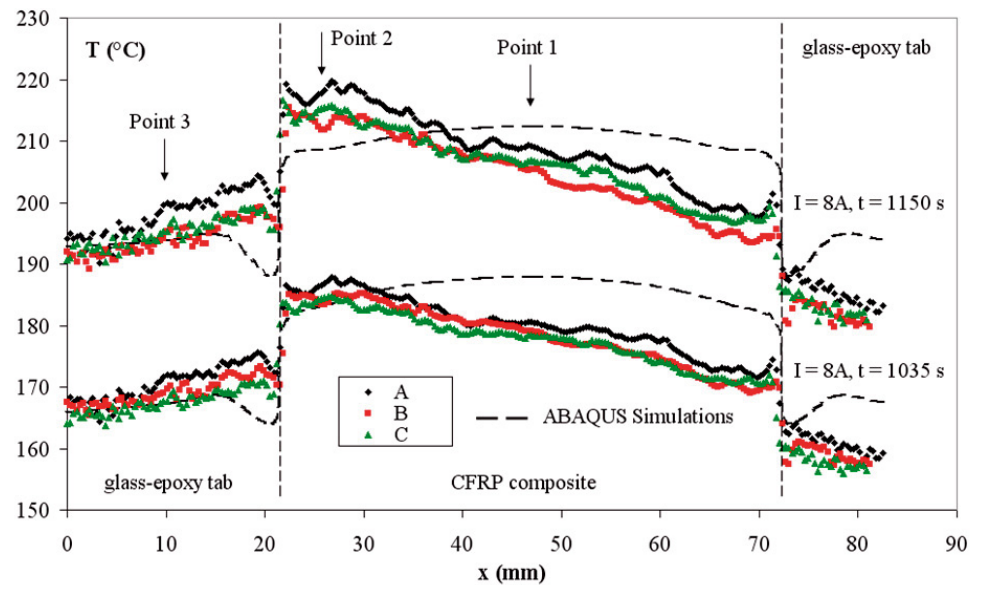

Fig. 13. Measured and ABAQUS ${ }^{\circledR}$ simulated profiles along the $x$ coordinate (Fig. 5a) at 8 A (and different times).

Equation (9) does not apply in the transient state since discards thermal conduction within the sample; it represents the equilibrium temperature of the CFRP as if all its thermal inertia and electrical resistance were concentrated in a single material point. This is why the model leading to Equation (9) is usually referred as lumped parameter model.

In Equation (9) $R_{\mathrm{s}}$ is the sample resistance, $i$ is the injected current density (the total current divided by $S_{\mathrm{p}}$, the section across which the current circulates), $S_{\mathrm{e}}$ is the exchange surface, the surface across which the specimen exchanges heat with the environment, $T$ is the equilibrium temperature of the sample, $T_{0}$ is the temperature of the environment (and, possibly, the initial temperature of the sample), $\varepsilon$ is the emissivity of the material, $\sigma$ is the StefanBoltzmann constant and $h$ is the coefficient of thermal convection.

It should be noted that, in Equation (9), $S_{\mathrm{e}}$ and $S_{\mathrm{p}}$ are geometrical parameters which can be easily measured; $R$ is a material parameter which can be measured by the test methods presented in Section 2 and - for a composite sample - calculated by Equation (4).

$\varepsilon, \sigma$ and $h$ are physical parameters which are usually well characterised in the literature, except $h$, which may depend on the environment in which testing is carried out and on the external temperature, for instance.

Equation (9) is an attractive way to assess the qualitative features of the thermoelectric behaviour of composite samples, to predict rapidly the temperatures of composite specimens traversed by electric currents, to perform parametric studies and to design thermoelectric tests.

For instance Equation (9) predicts that quite high equilibrium temperatures values have to be expected in composite samples traversed by relatively low currents (of the order of the A) and characterised by low values of the dissipated heat power (of the order of 40-50 W), such as those employed in the present work. In fact, in this case, the exchange surfaces are very small.

Figure 14 presents the equilibrium temperatures of points 1 and 2 (Fig. 6a) measured at the end of the transient state (Fig. 6b) and the temperatures predicted by
Equation (9) as a function of the injected DC current for a sample equipped with Prodec-type electrodes. Calculations are with $R=0.36 \Omega, \varepsilon=0.99$ and $T_{0}=20{ }^{\circ} \mathrm{C}$. Figure 14 shows also the average temperature values predicted by the ABAQUS ${ }^{\circledR}$ model.

In Figure 14 three different values of $h-$ all taken uniform and constant - are employed (between $5 \mathrm{~W} \cdot \mathrm{m}^{-2} \cdot{ }^{\circ} \mathrm{C}^{-1}$ and $10 \mathrm{~W} \cdot \mathrm{m}^{-2} \cdot{ }^{\circ} \mathrm{C}^{-1}$ ) for the simplified model, Equation (9).

The simulated curves with $h=5 \mathrm{~W} \cdot \mathrm{m}^{-2} \cdot{ }^{\circ} \mathrm{C}^{-1}$ and $h=8 \mathrm{~W} \cdot \mathrm{m}^{-2} \cdot{ }^{\circ} \mathrm{C}^{-1}$ bound from above and from below, respectively, the measured values of temperature.

The simulated curve with $h=10 \mathrm{~W} . \mathrm{m}^{-2} \cdot{ }^{\circ} \mathrm{C}^{-1}$ underestimates too much measured temperatures (especially at high values of the input current); the simulated curve with $h=5 \mathrm{~W} \cdot \mathrm{m}^{-2} \cdot{ }^{\circ} \mathrm{C}^{-1}$ gives conservative results.

It should be noted that the simulated curves capture very well the trend of the equilibrium surface temperatures as a function of the input current.

Moreover, the temperatures predicted by the simplified model compare well with the average equilibrium temperatures of the transient ABAQUS ${ }^{\circledR}$ numerical model, with the same exchange convection and radiation coefficients.

Therefore, the simplified model can be useful to assess the qualitative features of the thermoelectric behaviour of composite specimens, to predict rapidly the temperatures of composite samples traversed by electric currents, to perform parametric studies and to design thermoelectric tests.

\section{Conclusions}

The present paper has been focused on the thermoelectric response of T300/914 $\left[(0 / 90)_{4}\right]_{s}$ CFRP subjected to $\mathrm{DC}$ currents up to $8 \mathrm{~A}$ in view of developing experimental and modelling tools for the characterisation of the thermo-electro-mechanical behaviour of composite materials for aircraft applications. 


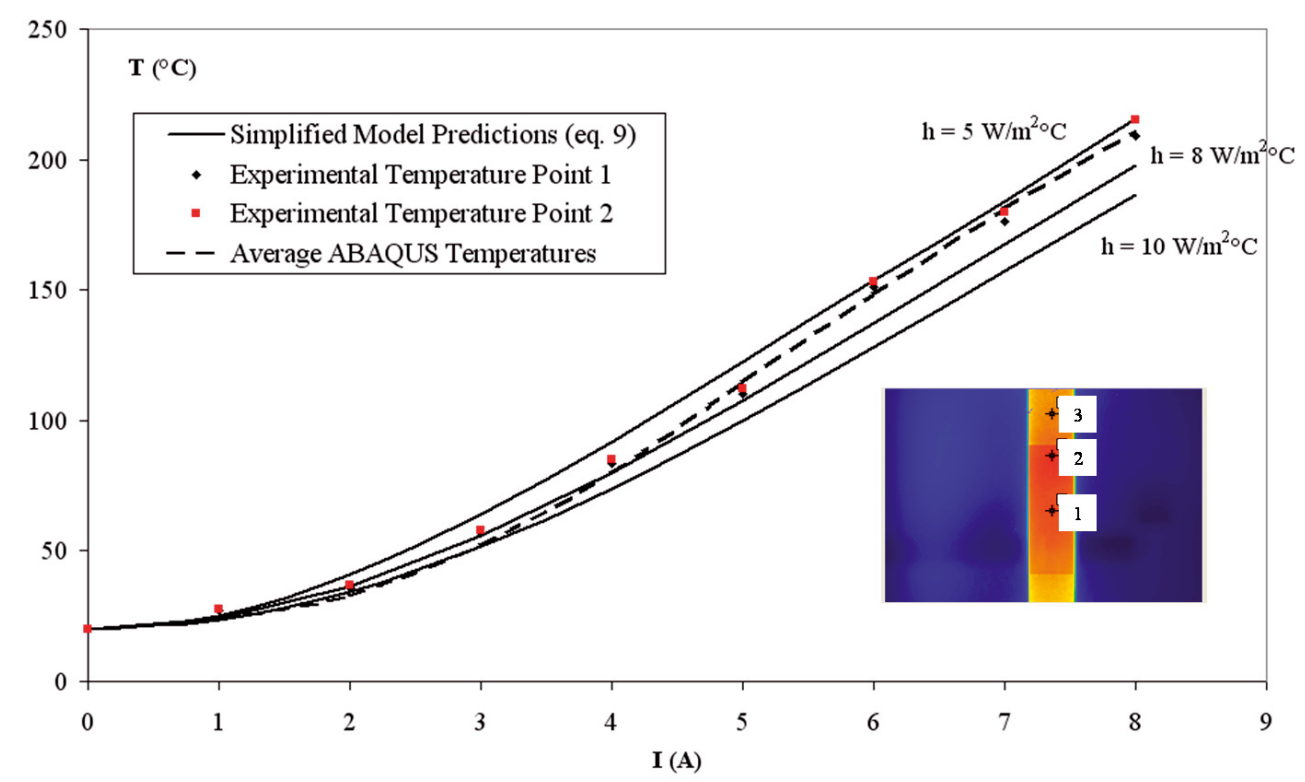

Fig. 14. Measured (points 1 and 2 Fig. 6a), Simplified model and average ABAQUS ${ }^{\circledR}$ predicted equilibrium temperatures as a function of the input current.

Thermoelectric tests have been performed on CFRP samples equipped with glass-epoxy tabs and traversed by $\mathrm{DC}$ current of the order of the A, up to $8 \mathrm{~A}$.

The temperature field has been fully characterised on the external surfaces of the specimens as a function of time by infrared thermography. Also the electric voltage has been measured as a function of the applied DC current.

The performance of different electrode techniques ("industrial-like" and "laboratory-like") has been assessed and compared.

For a sample equipped with "industrial-like" Prodectype electrodes the maximum measured temperature along the CFRP is around $215^{\circ} \mathrm{C}$ at $8 \mathrm{~A}$. This value of temperature is relatively high compared to typical glass transition temperature values of carbon-epoxy composites (between $160{ }^{\circ} \mathrm{C}$ and $200{ }^{\circ} \mathrm{C}$ ).

Temperature gradients have been measured on the surface of the samples, however:

- no localised heating has been noted close to the electrodes and to the electric contacts;

- along the CFRP the maximum temperature difference was small compared to the average temperature of the sample, at each time (around 13\% see Tab. 2).

These results are important because show that "industrial-like" technologies are effective for injecting currents of the order of the A into the composite sample. These techniques imply performing chemical polishing and copper electrodepositing on the composite sides through which the currents have to be injected. Laboratory-type solutions (typically, silver paints) are not effective at all for currents of the order of the A.

A linear relationship between the electric voltage and the input current has been experimentally found; a global resistance $R_{\mathrm{m}}=0.44 \Omega$ is measured for a sample of length $L_{x}=180 \mathrm{~mm}$. Voltage measurement tests performed on samples of different lengths allow determining the resistance of the sample "industrial-like" electrodes and of the electrical contacts, which globally amounts to around $0.08 \Omega$. These voltage measurements together with the hypothesis that the DC current circulates only along the $0^{\circ}$ ply fibres allowed identifying the coefficient of electrical resistivity of the fibre material whose value is in good comparison with that provided by the supplier datasheet.

Two coupled thermoelectric models have been employed for the interpretation and the simulation of the experiments.

The first model employs the ABAQUS ${ }^{\circledR}$ commercial finite element code and is able to simulate the transient behaviour of the sample, which can be complex depending on the geometry of the specimen and on the input current history.

The second model is based on a simple balance between the Joule dissipated power and the power exchanged with the environment by radiation and convection; it discards internal conduction within the specimen and is able to catch the average equilibrium temperature of the CFRP. This second model is useful to assess the qualitative features of the thermoelectric behaviour of composite specimens, to predict rapidly the temperatures of composite samples traversed by electric currents, to perform parametric studies and to design thermoelectric tests.

Both models - within the limits of their hypotheses are in satisfactory agreement with the experiments.

Acknowledgements. The present research was carried out within the context of the VICOMTHE research program financed by the French Research Foundation for Aeronautics 
and Space (FRAE) in collaboration with AIRBUS Toulouse, LGMT-UPS Toulouse and LIM ENSAM Paris. All partners of the research are gratefully acknowledged. The help of Damien Marchand, assistant engineer at the Institut Pprime - ENSMA, in developing and performing the experimental activity is also gratefully acknowledged.

\section{References}

[1] K. Schulte, C. Baron, load and failure analysis of CFRP laminates by means of electrical resistivity measurements, Compos. Sci. Tech. 36 (1989) 63-76

[2] J.C. Abry, S. Bochard, A. Chateauminois, M. Salvia, G. Giraud, In-situ detection of damage in CFRP laminates by electrical resistance measurements, Compos. Sci. Tech. 59 (1999) 925-935

[3] R. Schueler, S.P. Joshi, K. Schulte, Damage detection in CFRP by electrical conductivity mapping, Compos. Sci. Tech. 61 (2001) 921-930

[4] A. Todoroki, The effect of number of electrodes and diagnostic tool for monitoring the delamination of CFRP laminates by changes in electrical resistance, Compos. Sci. Tech. 61 (2001) 1871-1880

[5] J.B. Park, T. Okabe, N. Takeda, W.A. Curtin, Electromechanical modeling of unidirectional CFRP composites under tensile loading condition, Composites Part A: Appl. Scie. Manufacturing 33 (2002) 267-275

[6] Z. Xia, T. Okabe, J.B. Park, W.A. Curtin, N. Takeda, Quantitative damage detection in CFRP composites: coupled mechanical and electrical models, Compos. Sci. Tech. 63 (2003) 1411-1422
[7] N. Angelidis, C.Y. Wei, P.E. Irving, The electrical resistance response of continuous carbon fibre composite laminates to mechanical strain, Composites Part A: Appl. Sci. Manufacturing 35 (2004) 1135-1147

[8] D.D.L. Chung, Fibrous composite interfaces studied by electrical resistance measurement, Adv. Eng. Mater. 2 (2000) 788-796

[9] J. Park, S. Lee, J. Choi, Cure monitoring and residual stress sensing of single-carbon fiber reinforced epoxy composites using electrical resistivity measurement, Comp. Sci. Technol. 65 (2005) 571-580

[10] O.I. Zhupanska, R.L. Sierakowski, Effects of an electromagnetic field on the mechanical response of composites, J. Comp. Mater. 41 (2007) 633-651

[11] R.L. Sierakowski, I.Y. Telitchev, O.I. Zhupanska, On the impact response of electrified carbon fiber polymer matrix composites: effects of electric current intensity and duration, Comp. Sci. Technol. 68 (2008) 639-649

[12] http://www.prodecmetal.com, Last date accessed on the January 24, 2011

[13] http://www.tegma.fr/frechin/frechin.html, Last date accessed on the January 24, 2011

[14] http://www.jetmetal-tech.com, Last date accessed on the January 24, 2011

[15] ALTAIR CEDIP User Manual, Version 5. (c) 1989, 2006 CEDIP Infrared System

[16] ABAQUS 6.7 Users Manual, Version 6.3, (c) Hibbitt, Karlsson \& Sorensen, Inc. 2002

[17] TORAYCA T300 Technica Data Sheet

[18] HEXCEL Hexply 914 Product Data Sheet

[19] D. Gay, Matériaux Composites, Hermes, 1989 